\title{
Feasibility Study on Applications of Fermented Tea Extracts for Bioenergy and Biorefinery
}

\author{
An-Wei Hsu, Chung-Chuan Hsueh, Bor-Yann Chen* \\ Department of Chemical and Materials Engineering, National I-Lan University, I-La, Taiwan \\ Email address: \\ kimk@kimo.com (An-Wei Hsu), cchsueh88@gmail.com (Chung-Chuan Hsueh), boryannchen@yahoo.com.tw (Bor-Yann Chen) \\ *Corresponding author
}

\section{To cite this article:}

An-Wei Hsu, Chung-Chuan Hsueh, Bor-Yann Chen. Feasibility Study on Applications of Fermented Tea Extracts for Bioenergy and Biorefinery. Science Discovery. Vol. 5, No. 3, 2017, pp. 174-178. doi: 10.11648/j.sd.20170503.13

Received: January 20, 2017; Accepted: May 5, 2017; Published: May 11, 2017

\begin{abstract}
As known, tea contained abundant antioxidant compositions significant to human health due to major components of polyphenols and Flavonoids. Prior studies indicated that $-\mathrm{OH}$ substituent-rich aromatic compounds could might have electron shuttling capabilities for bioenergy recycling. Thus, it was suspected that antioxidant compositions would be crucial to bioelectrochemical characteristics to be expressed. Prior studies also revealed that decolorized intermediates evidently could enhance redox-mediating capabilities. Thus, it was suggested that such capabilities should be strongly associated to antioxidant and electron-transfer characteristics. For sustainable development, using naturally-present/generated and environmentally compatible plants as precursor(s) for further applications of recycling and reuses is more ecologically appropriate. Thus, this feasibility study tended to use myriads of fermented tea extracts for comparative study of bio-electrochemistry. Meanwhile, exploration of contents of antioxidants could provide further perspectives for applications in biofuel cells and functional foods. The findings also suggested that highly fermented tea extract would exhibit less electron-shuttling capabilities due to less content of polyphenolics remained in tea residues. In fact, this result was in parallel with the capabilities of antioxidants as revealed in literature. This findings could be used for diverse applications in bioenergy and biorefinery.
\end{abstract}

Keywords: Antioxidant, Electrochemistry, Electronic Shuttle, Bioenergy, Biorefinery

\section{發酵茶葉於生物能源及生物精煉上之可行性研究}

許安瑋, 薛仲娟, 陳博彥*

化學工程與材料工程學系, 宜蘭大學, 宜蘭市, 台灣

邮箱

kimk@kimo. com (許安瑋)， cchsueh88@gmail.com（薛仲娟）, boryannchen@yahoo.com. tw（陳博彥）

摘要: 眾所皆知, 茶葉具有益於人體健康之抗氧化物成分, 主要是由多酚和類黃酮分子構成之抗氧化成分。先前研究 指出含 $-\mathrm{OH}$ 官能基之芳香族化合物可能具有電子梭之中介能力, 可用於生物能源再利用之應用上。因此推論可能存在 著抗氧化成分及生物電化學相關特性。先前研究更指出染料脫色中間物確實可提升電子傳遞之能力, 因此合理推論此 種性質可能與其抗氧化性等電子傳遞作用有所關聯。但隨著綠色永續環保意識的抬頭, 選擇天然綠色環境生態相容之 可食用性植物作為前趨物原料, 更可有利於後續能源再利用精煉。因此本研究嘗試對多種不同發酵程度茶類進行生物 電化學評估比較分析, 以及對抗氧化活性之相關評估研究, 以利於後續深入評估應用於生物電池與醫藥及保健食品之 相關領域上。本研究發現茶類發酵程度越高實不利於電子傳遞特性之表達, 此點與文獻中指出之抗氧化活性平行正相 關, 主要原因可能在於含有較低之多酚類化合物所致。此結果可應用於生物能源及生物精煉上。 
关键词: 抗氧化物, 電化學, 電子梭, 生物能源, 生物精煉

\section{1. 引言}

文獻 [1]中指出與電化學活性相關聯之抗氧化能力與 電子梭能力可能是電子轉移相關之特性。先前研究 [15] 發現含 $-\mathrm{OH}$ 及 $-\mathrm{NH}_{2}$ 化學物質可具有能促進脫色及生物產 電之電子梭能力, 而且富含多酚類化合物之可食用性植物 類, 極可能具有生物電子梭特性。因此基於環境生態友善 性之永續考量, 自天然可食用植物中篩選出具類似電子梭 特性之相關物質, 已是目前綠色環境生物技術及能源生物 發酵製程上極重要之研究課題。另有文獻指出中國歷史悠 久之茶葉飲品更富含有多酚及類黃酩類等抗氧化物成分 存在, 可能具提神清腸整胃作用 $[2,3]$ 。再者, 電化學分 析研究更指出含兒茶素之茶葉, 亦具有氧化還原峰之電子 梭特性 $[4,5,6]$, 因此合理懷疑天然中草藥所含的色素可 能亦是電子移轉之發色基團, 且具有人體需要的營養物質 或可能具有豐富的藥膳作用, 例如: 綠茶、滇紅與普洱等 常見茶類, 其富含天然多酚、黃酮化合物被認為可能是促 進健康的植物化學物質, 就因其 (1) 具有優良的抗氧化活 性, 抗病毒, 抗癌, 抗發炎的特性, 和 (2) 優異之清除自 由基能力 $[2,3]$ 。再者, 當單一分子之茶類化合物經微生 物分解, 亦可能產生更多具有電化學特性衍生之酚類化合 物分子, 因此亦可能有更高之生物電化學特性。本研究尤 其對不同發酵程度的茶葉進行相關抗氧化與電化學研究, 並節選可能具有抗氧化能力的茶葉, 以利於進行後續應用 於保健食品之相關領域。本初考研究結果指出茶葉之發酵 程度對其產生之電化學特性影響極鉅。更發現抗氧化活性 與與電子梭特性, 實質上是彼此平行正相關的, 此發現更 可用於生物能量及生物精煉之相關綠色永續之鷹用上。

\section{2. 材料與方法}

\section{1 . 茶葉萃取 (水萃與酒萃)}

就永續發展而言, 茶葉由於是歷史悠久且低生物毒性 之天然飲料來源, 因此評估其再利用之可行性更加重要。 為利於評估, 本研究先取定未使用過之茶葉來進行評價。 首先將不同發酵程度的茶葉, 例如: 綠茶 (Camellia sinensis (L.) Kuntze)、普洱茶 (Camellia assamica (Mast.) Chang)、滇紅 (Camelliaboreali -yunnanica), 先取新鮮 $2.5 \mathrm{~g}$ 切碎磨細, 分別溶於 $50 \mathrm{~mL}$ 的 $50 \%$ 乙醇溶液 (Ethanol extract) 與50mL的蒸餾水 (Water extract) 兩種 萃取劑中, 浸泡 30 分鐘, 再以減壓濃縮在 $65^{\circ} \mathrm{C}$ 下煮沸 2 小 時, 進行抽氣過濾, 取其萃液, 再以去離子水將其定量至 $50 \mathrm{~mL} ，$ 以利後續評估分析。

\section{2. 循環伏安法}

將茶葉萃取液以氮氣去氧曝氣 15 分鐘, 後掃描 $1.5 \mathrm{~V}$ 到 $-1.5 \mathrm{~V}$, 速率為 $10 \mathrm{mV} \cdot \mathrm{s}^{-1}$ 。由於茶葉本為多元複方之混 合物, 因此以六次掃描觀察是否具有氧化還原峰, 再將具
有此特性之樣品, 再進行循環伏安 100 圈以觀察其峰隨時 間是否具有可逆性穩定變化趨勢。之後再比較微生物脫色 前後之電化學特性變化差異, 以利於比較分析。

\section{3. 菌株前培養}

本研究取定研究室自行篩選具有降解脫色偶氮染料 能力之菌株, Shewanella hal iot is WLP72, Aeromonas sp. NIU01, 加入經滅菌後LB培養基配成之培養液 $\left(25 \mathrm{~g} \mathrm{~L}^{-1}\right)$, 再將菌株分別加入培養液中, 進行兩次活化 12 小時之搖瓶 前培養馴化, 以利後續微生物降解研究。為檢測其天然植 物降解代謝物是否可具有促進生物產電之能力, 將活化後 的株菌菌液取 $1 \mathrm{~m} 1$ 及茶葉萃取液 $50 \mathrm{ml}$, 加入含 $50 \mathrm{ml}$, 兩倍 之 LB $(1: 1 \mathrm{~V}: \mathrm{V})$ 稀釋後搖瓶培養, 再以 $30^{\circ} \mathrm{C} 、 125 \mathrm{rpm}$ 條 件下搖瓶培養 12 小時後, 開始靜置 $20 \mathrm{hr}$ 以上使其萃液, 在厭氧條件下進行微生物降解, 以用於後續電化學分析試 驗。

\section{4. 微生物電池-交流阻抗與極化曲線}

本研究為確認其茶葉萃取液是否具有促進電子轉移 能力有效增進產電功率, 故藉由微生物燃料電池為平台來 檢測其功效。在電池達到穩定電壓輸出後, 使用線性伏安 法以進行極化曲線來量測 $[7]$ 。以WLP72殖種之微生物電池 在電化學量測前先量測量開路電壓 (即無外電阻條件下之 電壓值), 並以開路電壓值作為電位掃描之極值, 並作慢 速掃描（即掃描速率（scan rate） $\leqslant 1 \mathrm{mV} \mathrm{s}^{-1}$ ) 以獲得 極化曲線之數據, 極化曲線的量測範圍在 $O \mathrm{CV}^{\sim} 0 \mathrm{~V}$ 之間, 掃描速率為 $1 \mathrm{mV} \mathrm{s}$, 而輸出功率、功率密度及電流密度 的計算可由 $\mathrm{P}=\mathrm{U}^{2} / \mathrm{R}=\mathrm{IU} / \mathrm{A}$ ( $\mathrm{A}$ 為電池陽極面積) 來求得。

利用電化學交流頻譜儀（HIOKI 3522-50，Japan）以 測量MFCs 交流阻抗頻譜 (Electrochemical impedance spectroscopy, EIS), 以二極法MFCs陽極為工作電極, 陰 極為參考電極與輔助電極 $[9]$, 在穩定電壓輸出的開路條 件下, 頻率為 $10^{4}$ 至 $5 \times 10^{-3} \mathrm{~Hz}$ 進行正弦擾動振幅為 $10.0 \mathrm{mV}$ [8]。以獲得的阻抗圖 (EIS curve) 與 $\mathrm{x}$ 軸的 截距則為實際阻抗 (real impedance, $Z_{\mathrm{re}}$ ), 可作為電解質 電阻 (electrolyte resistance, $R_{\text {ele }}$ ) ; 而阻抗圖中的曲 線在 $\mathrm{x}$ 軸交點後的曲線投影長度是反應動力電阻 (kinetic resistance) 與質傳電 阻 (diffusion resistance) 之和 $\left(R_{\text {kin }}+R_{\text {diff }}\right)$ 將三者總和值則為電池 內阻 $R_{\text {in }}\left(R_{\text {elec }}+R_{\text {kin }}+R_{\text {diff }}\right)$ 藉由總和電阻以瞭解茶葉萃取液對 電池內阻之影響 $[9,10]$ 。

\section{5. DPPH抗氧化試驗}

取 $0.666 \mathrm{~mL}$ 的 $1 \mathrm{mMDPPH}$ (溶於 $95 \%$ 酒精) 的等分試樣溶液 加入石英比色杯中, 然後加入 $0.333 \mathrm{~mL}$ 不同濃度的茶葉萃 取液。在室溫下避光 $30 \mathrm{~min}$ 後, 在 $515 \mathrm{~nm}$ 測定吸光度。定義 對應於DPPH自由基清除的百分比的清除能力可由下式估 算測定: 


$$
\text { DPPH radical scavenging }=\left[1-\frac{\left(\mathrm{Abs}_{\text {sample }}-\mathrm{Abs}_{\text {blank }}\right)}{A b s_{\text {control }}}\right] \times 100
$$

其中 $A B S_{\text {sample }}$ 是DPPH與萃液之間經 $30 \mathrm{~min}$ 反應後的吸光 度, $\mathrm{ABS}_{\text {blank }}$ 是空白 $(0.333$ 毫升的萃液和 0.666 毫升溶劑) 而 $\mathrm{ABS}_{\text {control }}$ 的吸光度是 $(0.333$ 毫升溶劑和 $0.666 \mathrm{~mL}$ 的DPPH 溶液）(標準方法詳見 $[11]) 。$

\section{3. 結果與討論}

\section{1. 茶葉萃取方法評估}

首先評估不同萃取方法 (水萃與酒萃) 是否對茶萃取 效果有所影響, 何者方能萃取出較高含量之多酚類成分, 以利於後續促進電子移轉相關評估研究。首先將水萃與酒 萃的茶葉萃取汁液分別進行循環伏安法測試, 來確認是否 具有促進電子轉移的氧化還原峰。由圖1可發現無論是水 萃或是酒萃皆具有促進電子轉移的氧化還原峰, 但是水萃 顯然更優於酒萃, 具有較顯著的氧化還原峰, 其原因可能 為水浴萃取能提取較多較親水之酚類分子, 另外酚類結構 式中含有 $-\mathrm{OH}$ 鍵, 因此較易親水形成氞鍵而溶解, 故對水 溶解度高, 後續萃取皆採用水浴萃取為標準作業程序。

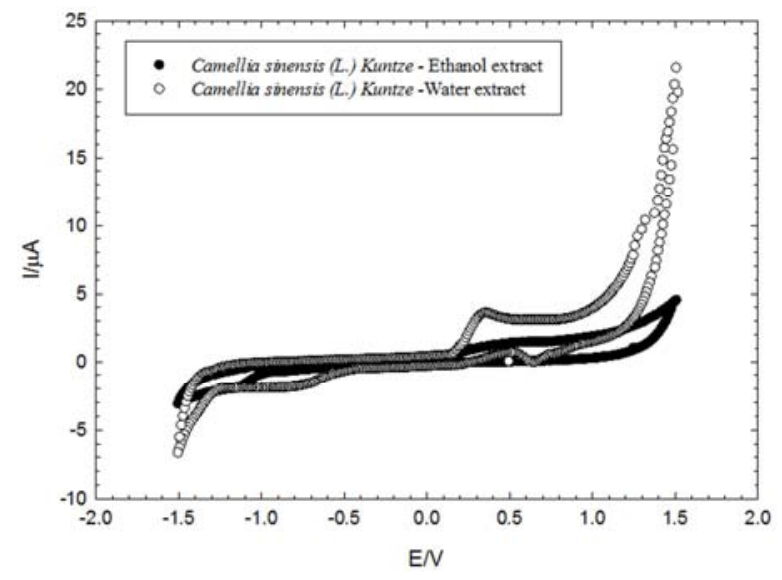

圖1 綠茶水萃與酒萃的循環伏安圖的比較。

\section{2. 微生物降解茶葉萃取液之電化學評估}

由於茶葉之品質差異可能在於發酵程度, 因此為評估 各種不同發酵程度茶葉萃取液經微生物轉化後是否具電 子梭之特性以促進電子轉移。先將茶葉萃取汁液與經 WLP72希瓦氏菌微生物處理後之茶葉萃取液分別進行循環 伏安法測試, 來觀察是否具有或增加促進電子轉移的氧化 還原峰大小。結果顯示 (圖2) 經過微生物處理後的萃液皆 優於未經微生物處理, 文獻指出 [12]經微生物處理後各種 大分子的茶多酚 (tea polyphenols) 會轉變為各種沒食子 酸和其他單體酚類化合物, 這些單體酚類具有更多可用的 羥基, 不僅可用於增加抗氧化能力, 其貢獻質子的能力更 可促進電子轉移 $[13]$, (如圖3所示), 而且未發酵茶綠茶 (Camellia sinensis (L.) Kuntze) 優於全發酵茶普洱茶 (Camellia assamica (Mast.) Chang) 與 滇 紅 (Camelliaboreali-yunnanica)。代表發酵程度越高實不
利於生物電化學特性之表達。此點與文獻上指出高發酵程 度實不利於多酚類化合物之存在亦有所關聯。後續會試驗 不同菌株對不同發酵程度茶葉的電化學影響, 以及生物能 源及電化學啟動發酵及生物精煉之永續應用研究上。
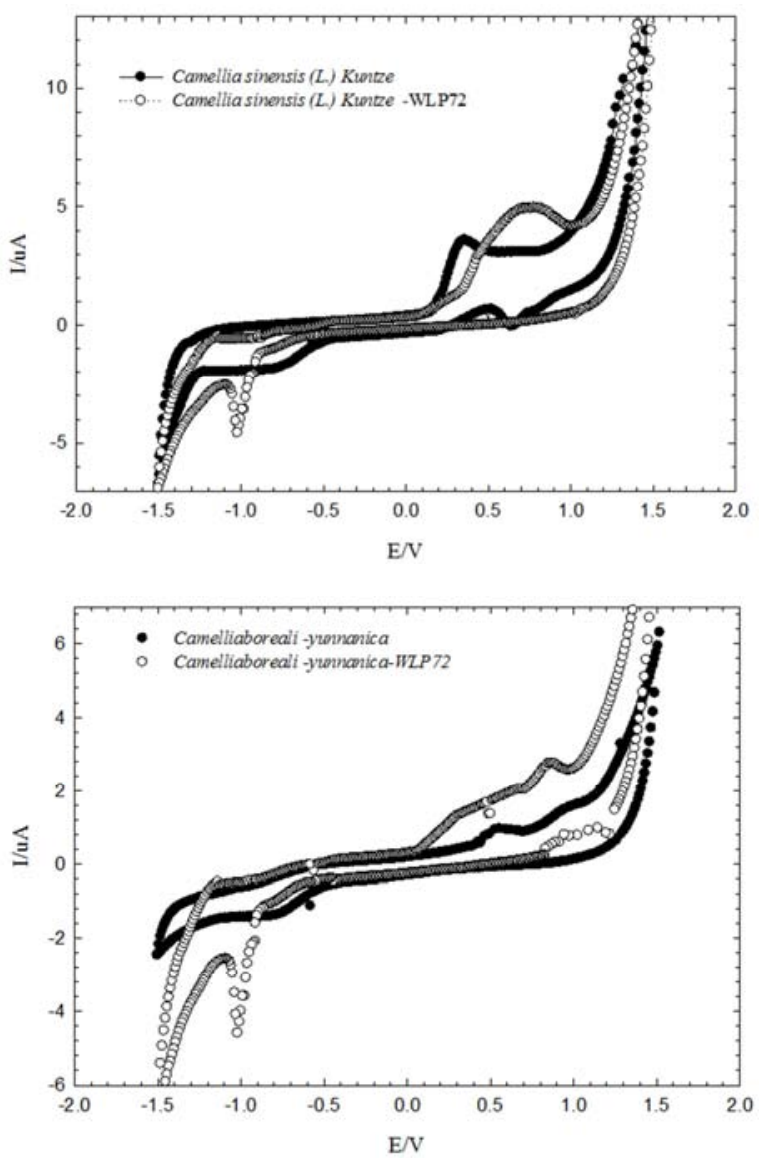

圖2 Shewanella sp (WLP72) 菌株處理前後的綠茶 (Came11ia sinensis (L.) Kuntze) 和紅茶 (Camelliaboreali-yunnanica) 萃取物的循環伏 安圖的比較。

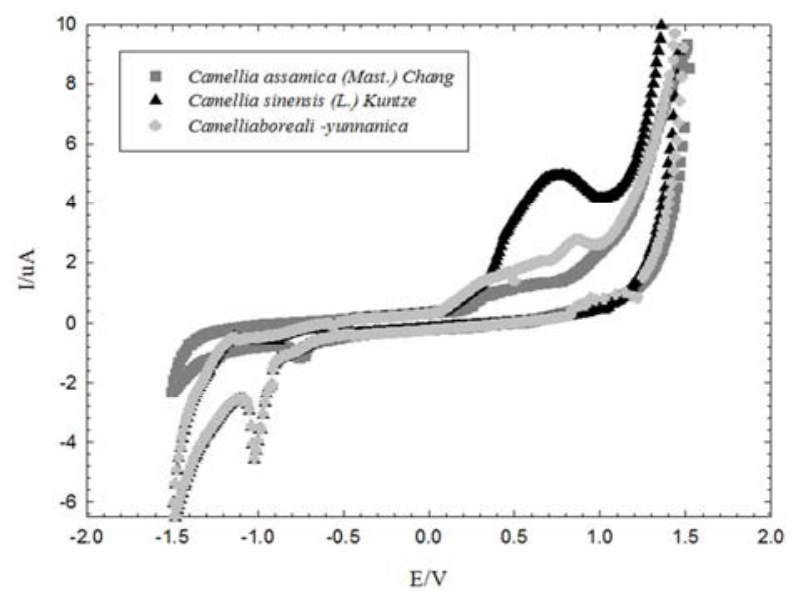

圖3 不同發酵程度茶葉(綠茶、普洱茶、滇紅) 萃取液經希瓦氏菌WLP72 微生物處理前後之循環伏安圖比較。 


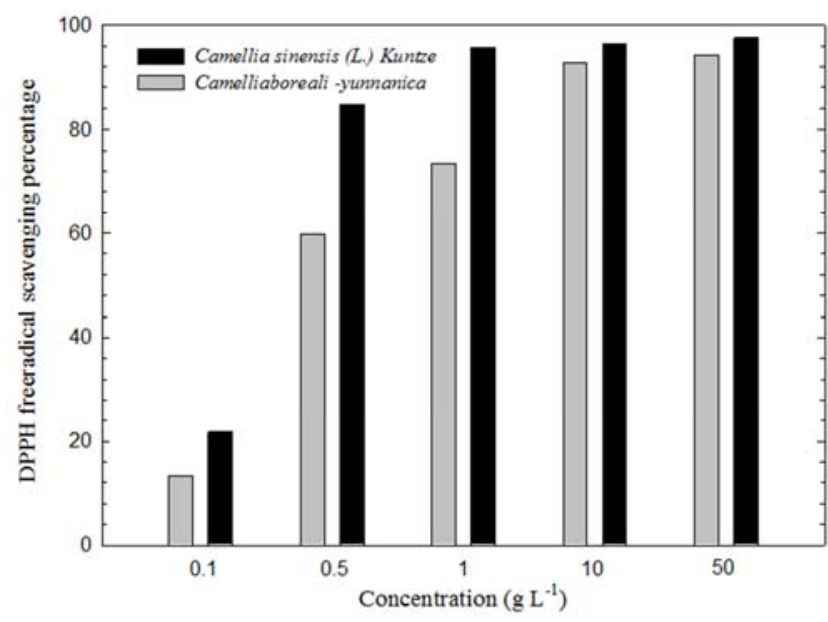

圖4 不同濃度 $\left(0.1 、 0.5 、 1 、 10 、 50 \mathrm{~g} \mathrm{~L}^{-1}\right)$ 的茶萃物 (綠茶、滇紅) 在 30 分鐘內, $1 \mathrm{mM}$ 濃度的DPPH溶液中其自由基清除率。

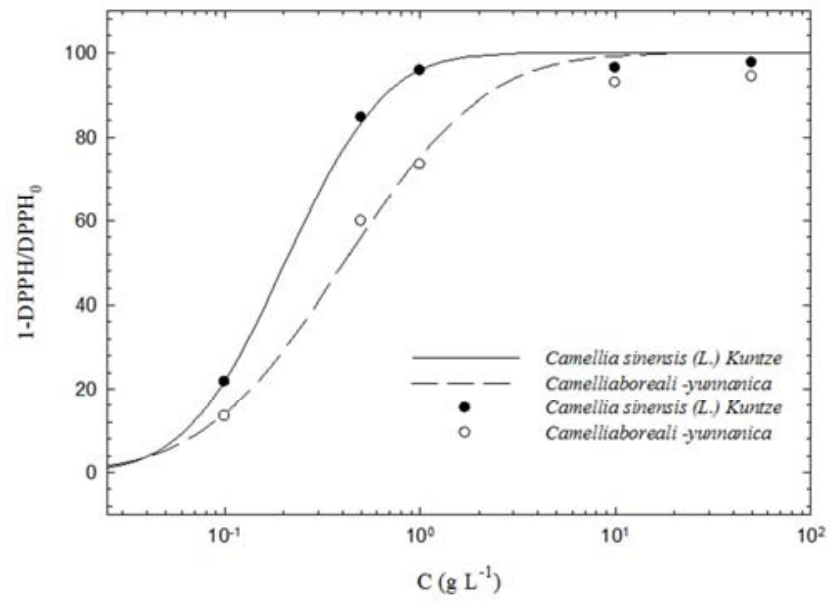

圖5 不同濃度 $\left(0.1 、 0.5 、 1 、 10 、 50 \mathrm{~g} \mathrm{~L}^{-1}\right)$ 的茶萃物 (綠茶、滇紅) 在 30 分鐘時之清除DPPH自由基的劑量反應曲線比較圖。

\section{3. 茶葉萃取液-抗氧化能力評估}

為確定抗氧化與電子轉移之關聯性, 故將不同濃度 $\left(0.1 、 0.5 、 1 、 10 、 50 \mathrm{~g} \mathrm{~L}^{-1}\right)$ 的綠茶與滇紅萃取液進行清 除DPPH自由基的抗氧化能力試驗, 由圖 4 可看出當茶萃液 濃度增加，隨著多酚類化合物濃度增大，其DPPH自由基之 清除效率亦隨之上升。圖 5 及表一更指出以茶葉在約 $0.2 \sim 0.4 \mathrm{~g} \mathrm{~L}^{-1}$ 即具 $\mathrm{EC}_{50}$ 之清除效果, 由B值大於 1 更可看出茶 葉自由基清除效果是相當有效的。而且未發酵茶(綠茶) 無論在何種濃度下其抗氧化能力皆優於發酵茶 (滇紅), 圖 五之劑量響應曲線亦明顯指出綠茶 (位於右邊之曲線) 具 較高之抗氧化消除活性 $\left(\mathrm{EC}_{50}\right.$ ：0.203g L $\mathrm{L}^{-1}$ (綠茶) $<0.408$ $\mathrm{g} \mathrm{L}^{-1}$ (滇紅) ), 兩者之響應曲線方程式分別為 $Y=6.74+2.51$ $\log Z$ （綠茶） $Y=5.69+1.77 \log Z$ （滇紅）（評估方法詳見 文獻 $[14])$, 而該結果也與預期猜測具有較強氧化還原電 子梭特性之茶葉其抗氧化能力也越強相符, 其原因可能為 抗氧化是電子轉移的過程, 而具有較強電子梭特性的茶葉 其電子轉移能力也更強, 故兩者之間為正相關之趨勢, 代 表富含多酚化合物之抗氧化活性確實具有電化學特性。
表1 以 “自由基清除” 為評價指標定義出之劑量響應關係式及有效濃 度劑量 (單位: $\mathrm{g} \mathrm{L}^{-1}$ ) 比較。

\begin{tabular}{lllll}
\hline & $\mathrm{EC}_{0}$ & $\mathrm{EC}_{20}$ & $\mathrm{EC}_{50}$ & $Y=A+B \log Z$ \\
\hline 綠茶 & 0.022 & 0.094 & 0.203 & $Y=6.74+2.51 \log Z$ \\
滇紅 & 0.017 & 0.137 & 0.408 & $Y=5.69+1.77 \log Z$ \\
\hline
\end{tabular}

3. 4. 茶葉萃取液-交流阻抗與級化曲線 (MFC)

表2 微生物染料電池添加不同發酵程度茶葉之交流阻抗。

\begin{tabular}{|c|c|c|c|}
\hline MFC condition & $\mathrm{R}_{\text {elec }}(\Omega)$ & $\mathrm{R}_{\mathrm{kin}}+\mathrm{R}_{\text {diff }}(\Omega)$ & Total $\mathrm{R}_{\text {in }}(\Omega)$ \\
\hline Blank & 11.95 & 461.90 & 473.85 \\
\hline $\begin{array}{l}\text { Camellia sinensis } \\
\text { (L.) Kuntze }\end{array}$ & 11.76 & 314.53 & 326.29 \\
\hline $\begin{array}{l}\text { Camellia assamica } \\
\text { (Mast.) Chang }\end{array}$ & 14.59 & 452.32 & 466.91 \\
\hline
\end{tabular}
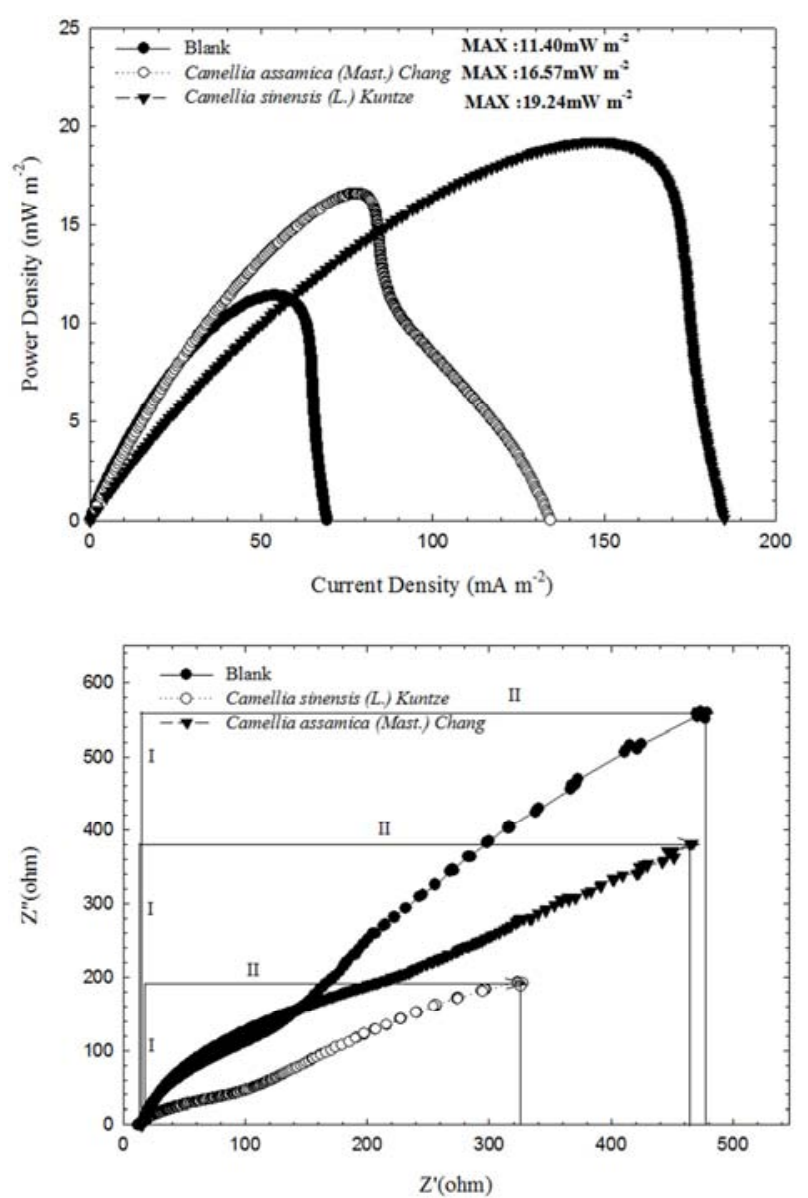

圖6 以WLP72殖種之微生物燃料電池來評估之綠茶與普洱極化曲線與交 流阻抗圖 (内)。

再者, 圖6更可看出當隨添加不同發酵程度的茶葉後, 其功率密度由原本未添加之 $11.40 \mathrm{~mW} \mathrm{~m}$ 提升至 $16.57 \mathrm{~mW}$ $\mathrm{m}^{-2}$ (普洱茶Camellia assamica (Mast.) Chang) 及19.24 mW $\mathrm{m}^{-2}$ (綠茶 Camellia sinensis (L.) Kuntze), 可看出添 加茶葉萃取液皆能使其功率密度提升越多, 尤其是未發酵 茶葉(綠茶Camellia sinensis (L.) Kuntze) 更為顯著。

然而圖五與表 2 可得知, 其交流阻抗則會隨著添加之 茶葉萃取液而降低, 且發酵程度越低其降低交流阻抗的能 力越強。事實上, 文獻中即指出 
(http://www. sciencedirect. com/science/article/pii /S0308814603000669) 未發酵茶中與半發酵茶富含聯苯三 酚基團 (pyrogallol groups) 與兒茶酚 (catechol) 和沒食 子酸酯基團 (gallate groups) 等促進電子轉移的成份, 而 發酵茶則因為發酵製程的原因，可能將各種多酚 (polyphenols) 轉變為茶黃素 (theaflavins) 進而降低促 進電子轉移的功效。因此未來在運用於食品保鮮或是在生 物能量及精煉上, 宜取用低發酵茶, 其抗氧化及電子中介 作用為最佳, 更有利生物能源相關之生物精煉應用。

\section{4. 結論}

未經微生物降解處理的茶萃取物比較發現, 電化學特 性是綠茶>普洱。經WLP72微生物處理後更可顯示出具顯著 電子轉移能力, 代表茶提取物確實可有效地表現氧化還原 中介能力並刺激MFC發電, 不過因發酵作用, 茶可能會減 弱茶提取物的ES能力。進一步的研究將尋求具高富含 ES 之植物提取物作為增強劑或刺激劑來刺激MFC和進一步的 生物煉製應用中生物能源再利用, 後續研究將探討電子梭 性質表現之最佳條件 (例如: 萃取溫度與萃取環境, 例如: $\mathrm{pH}$ 、溫度等), 並證明其能促進電子轉移與抗氧化能力之 相關佐證, 並定義最佳化之應用條件及可能應用之生物能 源及精煉相關領域。

\section{致谢}

感謝科技部計畫: 以東北部台灣本土生物資源應用於 功能性生物技術之可行性研究 (MOST 104-2622-E-197 -006 -CC3, MOST 105-2622-E-197-012-CC3; MOST 105-2221-E-197-022) 之經費補助。

\section{参考文献}

[1] B. Y. Chen, C. C. Hsueh, Deciphering Electron Shuttles for Bioremediation and Beyond. American Journal of Chemical Engineering, 4(5), 2016, pp. 114-121.

[2] D. Zhao, N. P. Shah. Antiradical and tea polyphenol-stabilizing ability of functional fermented soymilk-tea beverage. Food Chemistry, 158 (1), 2014, pp. 262-269.

[3] G. Rusak, D. Komes, S. Likić, D. Horžić, M. Kovač. Phenolic content and antioxidative capacity of green and white tea extracts depending on extraction conditions and the solvent used. Food Chemistry, 110 (4), 2008, pp. 852-858.

[4] A. Masek, M. Zaborski,. E. Chrzescijanska,. Electrooxidation of flavonoids at platinum electrode studied by cyclic voltammetry. Food Chem, $127(2)$, 2011, pp. 699-704.
[5] R. d. Q Ferreira, S. J Greco, M Delarmelina, K. C. Weber,. Electrochemical quantification of the structure/antioxidant activity relationship of flavonoids. Electrochimica Acta, 163, 2015, pp. 161-166.

[6] 0 Makhotkina, P. A Kilmartin,. The use of cyclic voltammetry for wine analysis: determination of polyphenols and free sulfur dioxide. Anal Chim Acta, 668(2), 2010, pp. 155-65.

[7] B. E Logan, J. M. Regan, "Electricity-producing bacterial communities in microbial fuel cells," Trends in Microbiology, 14, 2006,. pp. 512-518.

[8] Y Zuo, D. Xing, J. M Regan, B. E Logan,. Isolation of the Exoelectrogenic Bacterium 0chrobactrum anthropi YZ-1 by Using a U-Tube Microbial Fuel Cell. Appl. Environ. Microbiol., 74(10), 2008, pp. 3130-3137.

[9] Y Sharma, B Li, “The variation of power generation with organic substrates in single-chamber microbial fuel cells (SCMFCs), ” Bioresource Technology, 101, 2010, pp. 1844-1850.

[10] E. Katz, I Willner, "Probing Biomolecular Interactions at Conductive and Semiconductive Surfaces by Impedance Spectroscopy: Routes to Impedimetric Immunosensors, DNA-Sensors, and Enzyme Biosensors, ” Electroanalysis, 15, 2003, pp. 913-947.

[11] K. F. Gracy, F. Oliveir, T. Tormin, M. F. Raquel Sous, Alberto de 0liveir, Sérgio A. L. de Morais, Eduardo M. Richter, Rodrigo A. A. Munoz. Batch-injection analysis with amperometric detection of the DPPH radical for evaluation of antioxidant capacity. Food Chemistry, $192(1)$, 2016, pp. 691-697.

[12] R. Tabasco, F. Sánchez-Patán, M. Monagas, B. Bartolomé, B. V. Moreno-Arribas, C. Peláez, T. Requena. Effect of grape polyphenols on lactic acid bacteria and bifidobacteria growth: Resistance and metabolism. Food Microbiology, 2011, 28(7), pp. 1345-1352.

[13] Y. Yilmaz , R. T. Toledo. Major Flavonoids in Grape Seeds and Skins: Antioxidant Capacity of Catechin, Epicatechin, and Gallic Acid. J. Agric. Food Chem., 2004, 52 (2), pp. $255-260$.

[14] Bor-Yann Chen, Hsuan-Liang Liu, Yun-Wen Chen, Yang-Chu Cheng. Dose-response assessment of metal toxicity upon indigenous Thiobacillus thiooxidans BC1, Process Biochemistry, 39(6), 2004, pp. 737-748.

[15] B. Y. Chen, C. C. Hsueh, S. Q. Liu, J. Y. Hung, Y. Qiao, P. L. Yueh, Y. M. Wang. Unveiling characteristics of dye-bearing microbial fuel cells for energy and materials recycling: Redox mediators, International Journal of Hydrogen Energy, 38(35), 2013, pp.15598-15605. 